\title{
EXPERIMENTAL RESULTS OF
}

HIGH POWER DOUBLE-PASS, DOUBLE CLAD EYDFA

T. ARAKI*, E. MIZUTA, Y. KOBAYASHI, A DIRECTORATE OF R\&D, JAXA Y. TAKUSHIMA, $X$. WANG, S. SEKIGUCHI OPTOQUEST CO., LTD., 


\section{CONTENTS}

1. Back ground

2. Purpose of this research

3. Design and Fabrication of Double-Path, Double-Clad EYDFA

4. Experimental results

5. Conclusion 


\section{Back ground}

2. Purpose of this research

3. Design and Fabrication of Double-Path, Double-Clad EYDFA

4. Experimentäl results

5. Conclusion 


\section{Back Ground}

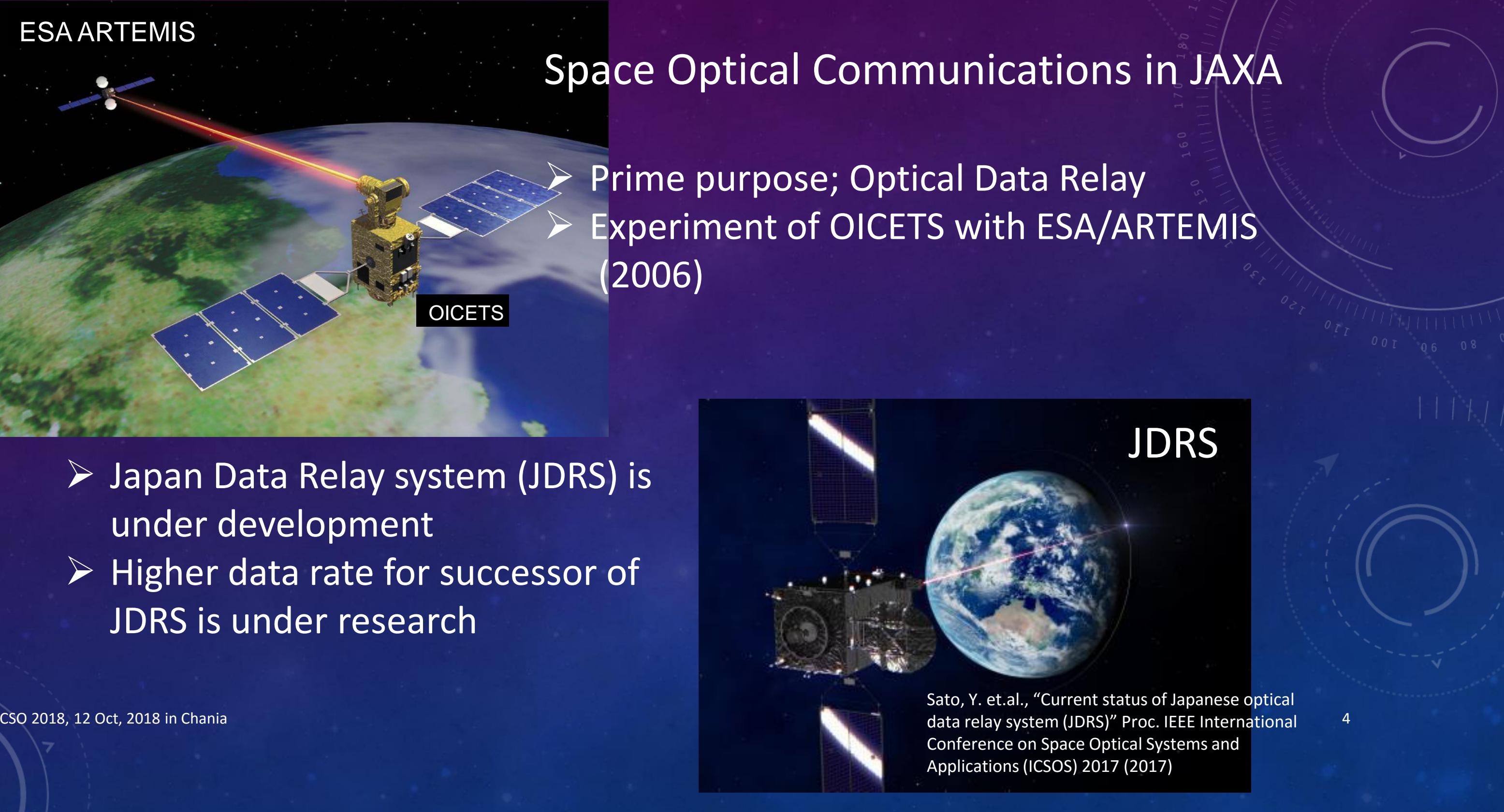




\section{Back Ground (cont')}

Our Research activities are as follows;

I. International Standardization in CCSDS

$>$ HDR 1.5um (1.5um band, PSK, and DVB-S2)

activities with NASA, CNES, NICT

$>$ Coding and Sync (C\&S) proposal for Optical On-Off Keying (O3K) based on Japanese private sectors proposal

for 100ME user, dedicate RS x ILV x RS, proposed by SONY for 10GE user, proposed from NEC

If you are interested in our C\&S proposal, please contact me later (in lunch, coffee brake, and dinner). 


\section{Back Ground (cont')}

Our Research activities

I. International Standardization in CCSDS

$>$ HDR 1.5um (1.5um band, PSK, and DVB-S2) activities with NASA, CNES, NICT

$>$ Coding and Sync proposal for Optical On-Off Keying (O3K) based on Japanese private sectors proposal for 100ME user, dedicate RS $\times$ ILV $\times$ RS, proposed by SONY for 10GE user, proposal from NEC

Scope of this presentation

\section{High performance transmitter and receiver}

III. Safety and "Flexible operation to avoide cloud blocking" of Optical Ground Station. 


\section{Back Ground (cont')}

- The primary objective of JAXA's optical communication technology research is to establish $20 \mathrm{G}$ bps optical data relay system in later part of 2020s.

$\checkmark$ Technology will apply on vHTS

\section{$\lambda: 1550 \mathrm{~nm}$ band}

Optical Inter-Satellite Link Return;

2.5G bps, 5G bps, 10G bps or $20 \mathrm{Gbps}$

\section{$>10$ W Optical}

HPA is

required

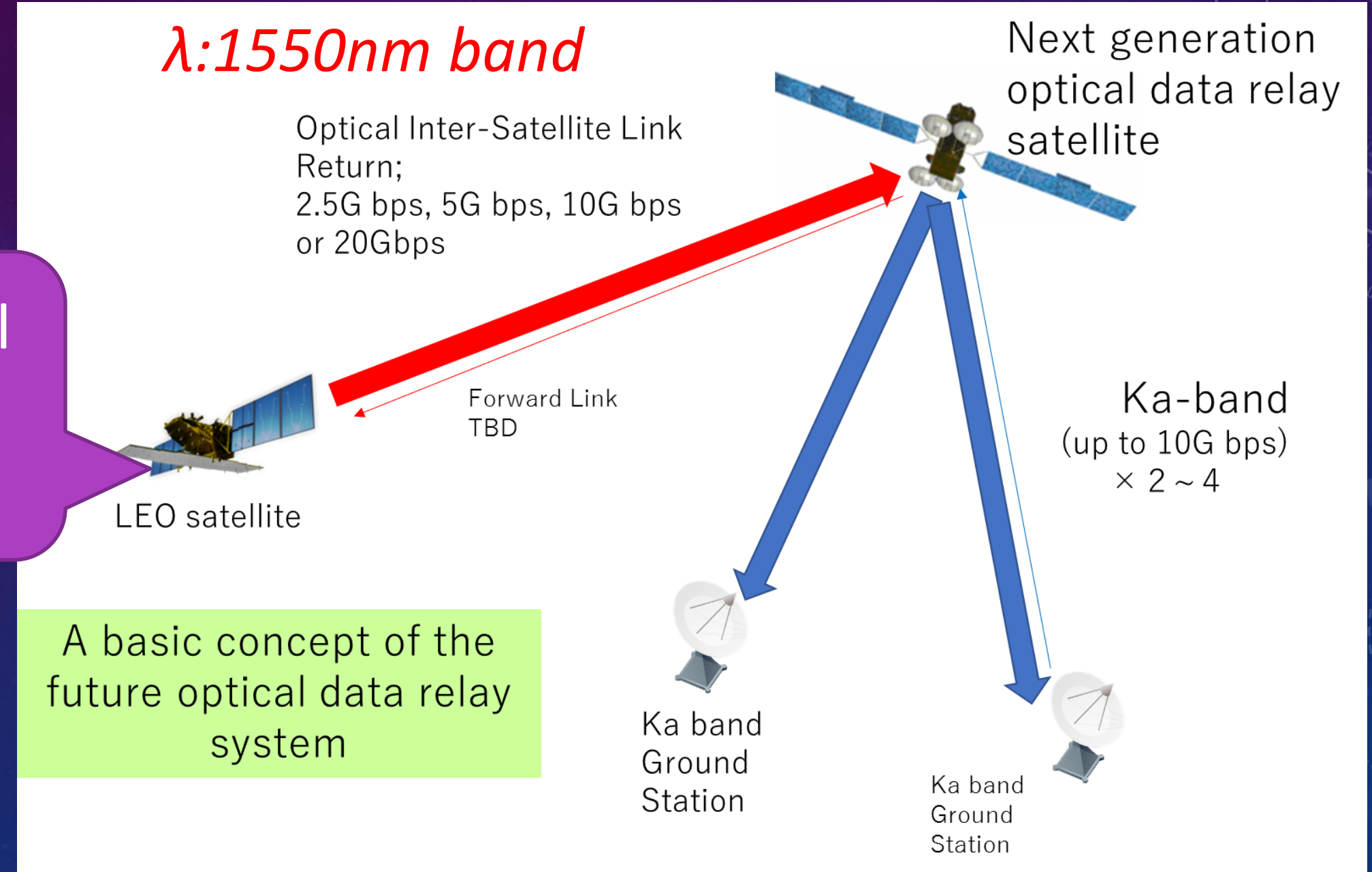

Araki, T. "A study of the future optical data relay system; requirements, problems and solution" Proc. of 2017 IEEE International Conference on Space Optical Systems and Applications (ICSOS) 2017 (2017) 
1. Back ground

2. Purpose of this research

3. Design and Fabrication of Double-Path, Double-Clad EYDFA

4. Experimental results

5. Conclusion 


\section{Purpose of this research}

Transmitter

\begin{tabular}{c|l|l|l}
$\begin{array}{c}\text { DFB-LD \& } \\
\text { Phase } \\
\text { modulator }\end{array}$ & WDM & HPA & $\begin{array}{c}\text { OPTICAL } \\
\text { ANTENA }\end{array}$ \\
\hline
\end{tabular}

Receiver

OPTICAL

ANTENA 


\section{Purpose of this research}

Transmitter

DFB-LD \&
Phase
modulator

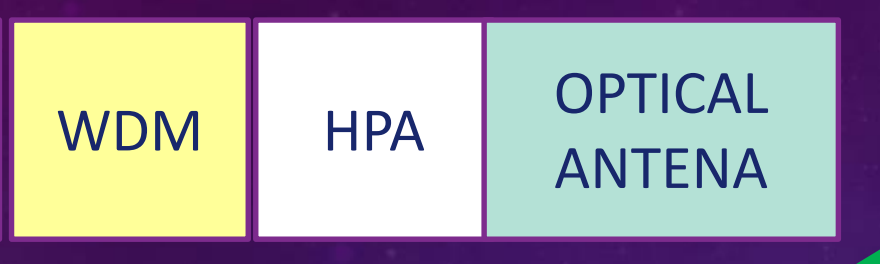

modulator

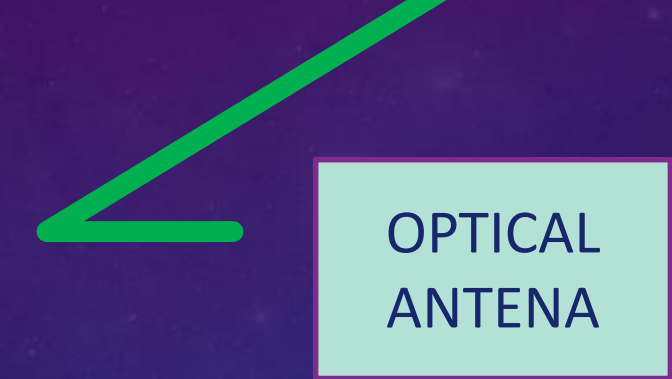

Receiver

LNA

WDM

Demodulator

Rich heritage of optical fiber communications

Based on space optics heritage

NEEDS High Speed Digital Devives

For "Digital Coherent" 
On ground use, even if ultra high spped long-haul fiber com, HPA is up to $30 \mathrm{dBm}$ and do not need high efficiency (Plug to Optical)

UNIQUE REQUIREMENT on HPA for space optical comm.

$>+40 \mathrm{dBm}$, high efficient, and radiation \& vacuum tolerant.

\section{Transmitter}
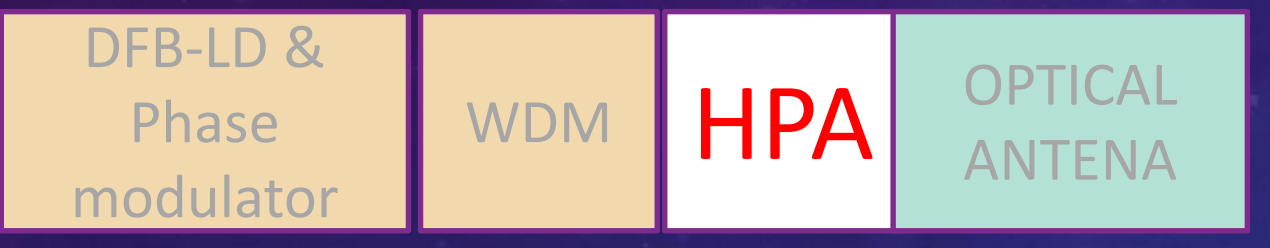

Receiver
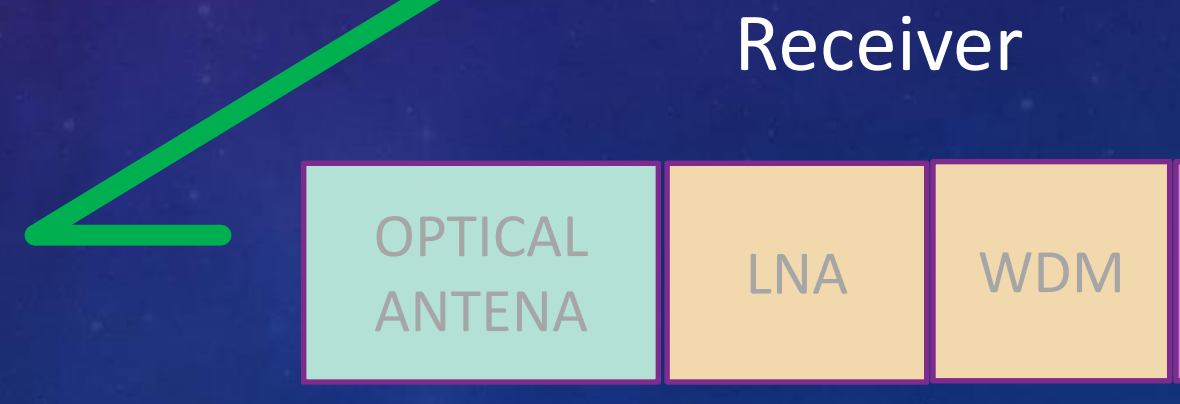


\section{Outline and scope of our optical HPA research}

1. Higher Efficient

Present; Efficiency (Plug to optical) is up to applox. 10\%, using conventional 2 or 3 stage EYDFA

To improve efficiency, we Investigate Double-path (DP), Double Clad (DC) EYDFA

Advantage of DP;

$>$ Expected higher efficiency and gain.

$>$ Polarization maintained and multi W optical HPA will be realize without PM-DC-EYDF.

We conduct experimental research of DC-DP-EYDFA. (This presentation)

2. Radiation Tolerant

Kobayashi, Y. et. al., "Effects of Ge Co-Doping on P-Related Radiation-Induced Absorption in Er/Yb-Doped Optical Fibers for space application" IEEE Journal of Lightwave Technologies Volume: 36, Issue:13 PP2723-2729 (2018) 


\section{Back ground}

2. Purpose of this research

3. Design and Fabrication of Double-Path, Double-Clad EYDFA

4. Experimental results

5. Conclusion 


\section{Designed DP-DC-EYDFA for experiments in laboratory.}

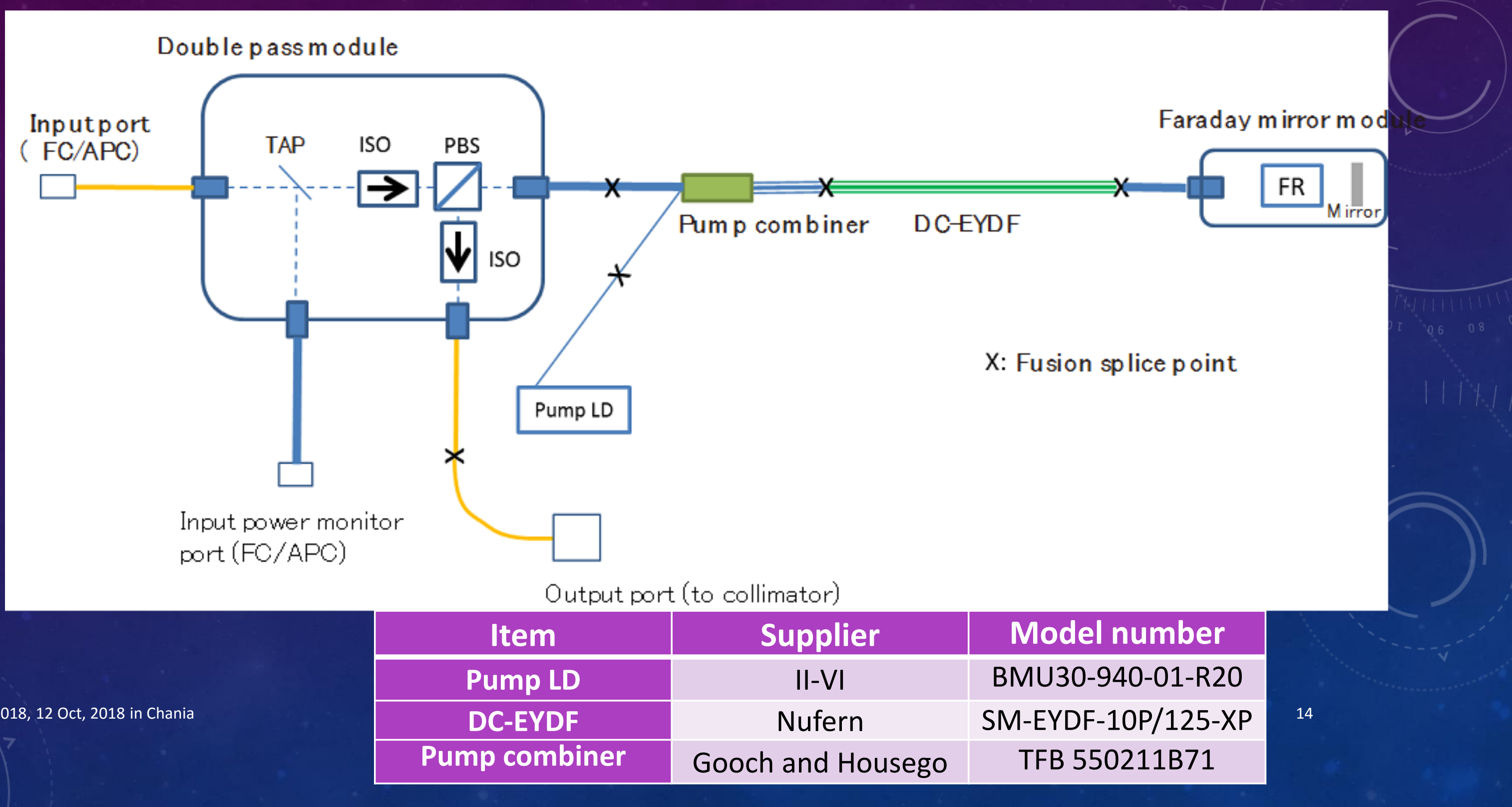




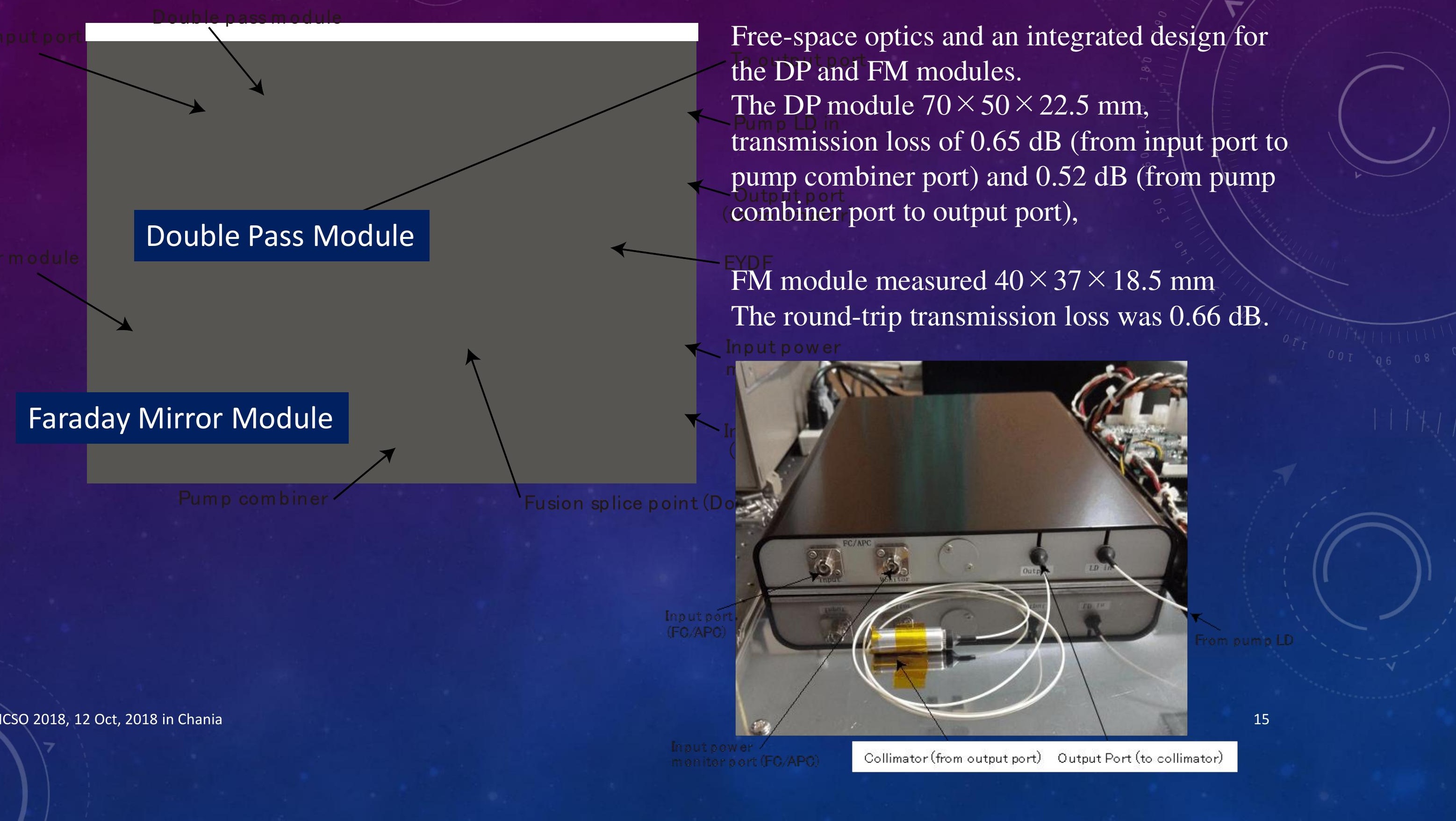


1. Back ground

2. Purpose of this research

3. Design and Fabrication of Double-Path, Double-Clad EYDFA

\section{Experimental results}

5. Conclusion 


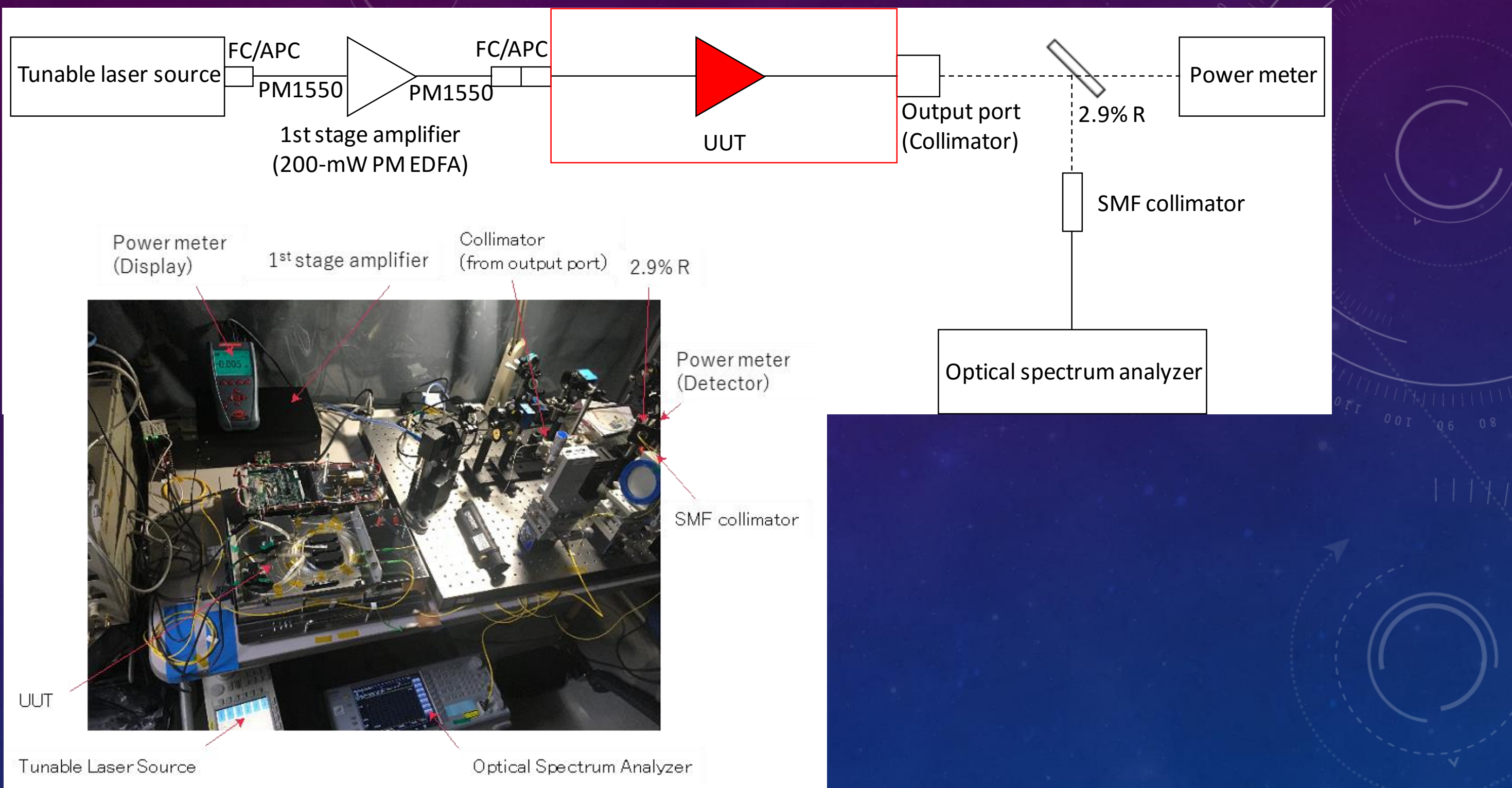




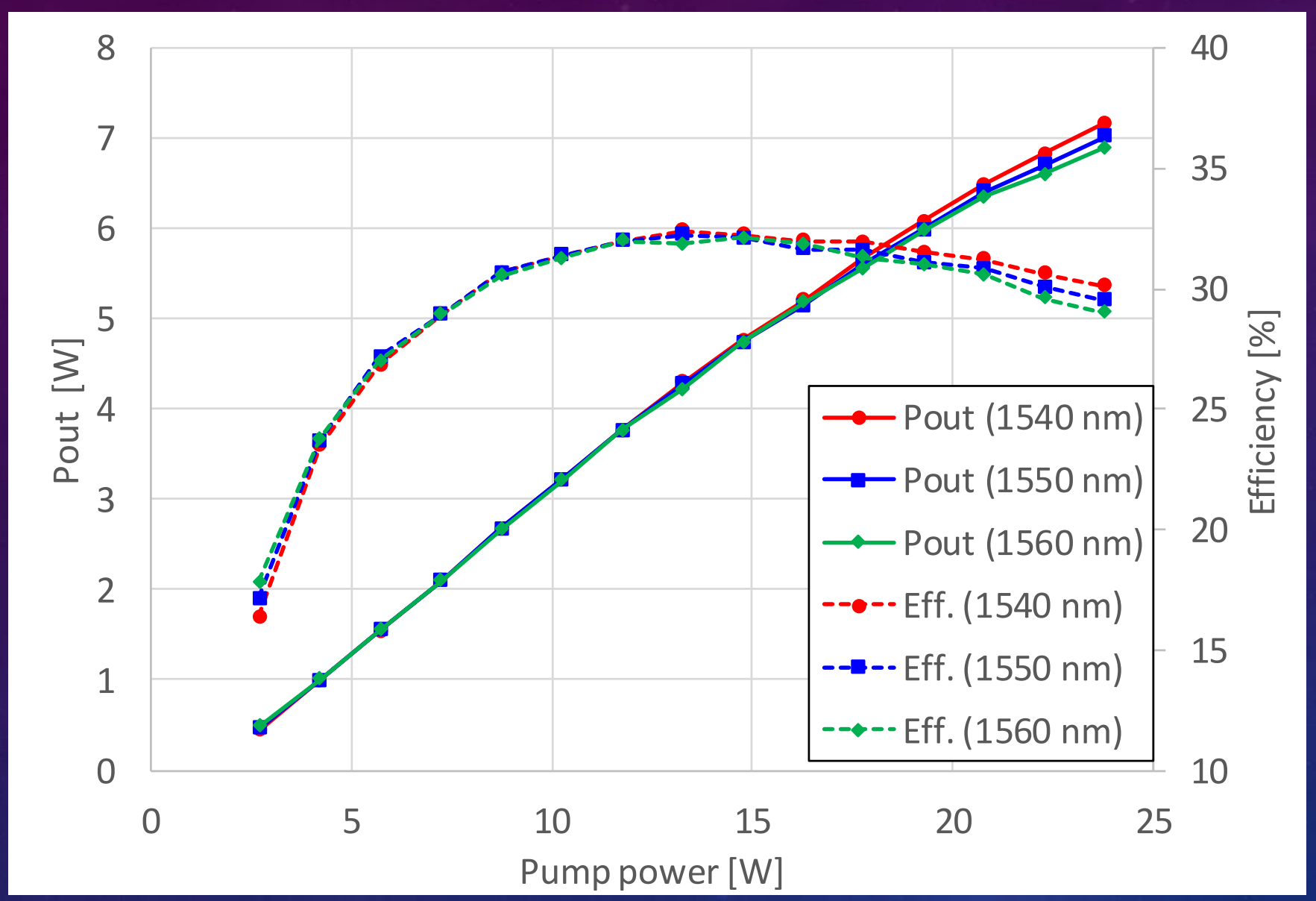




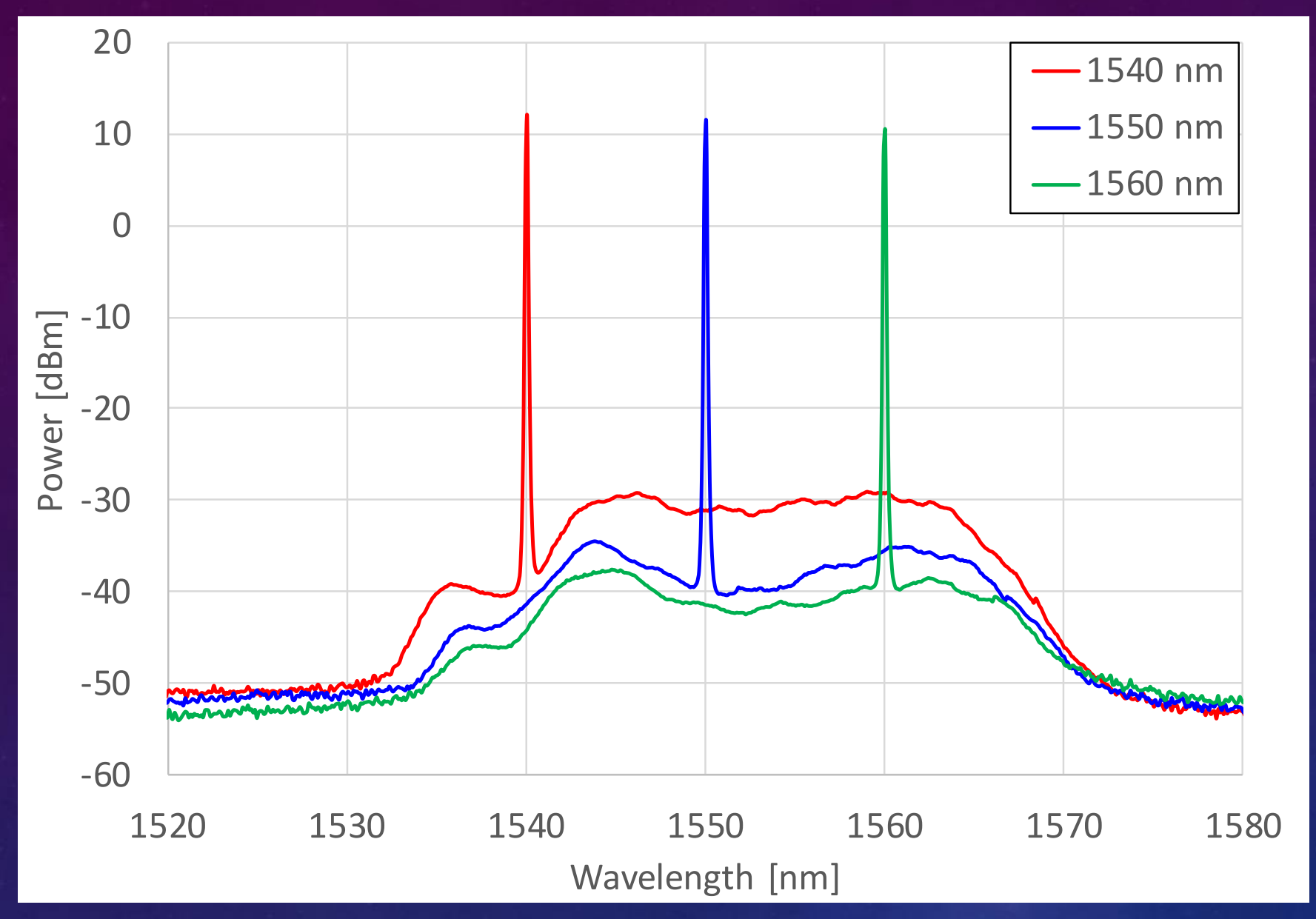




\section{Single-Pass measurements setup}

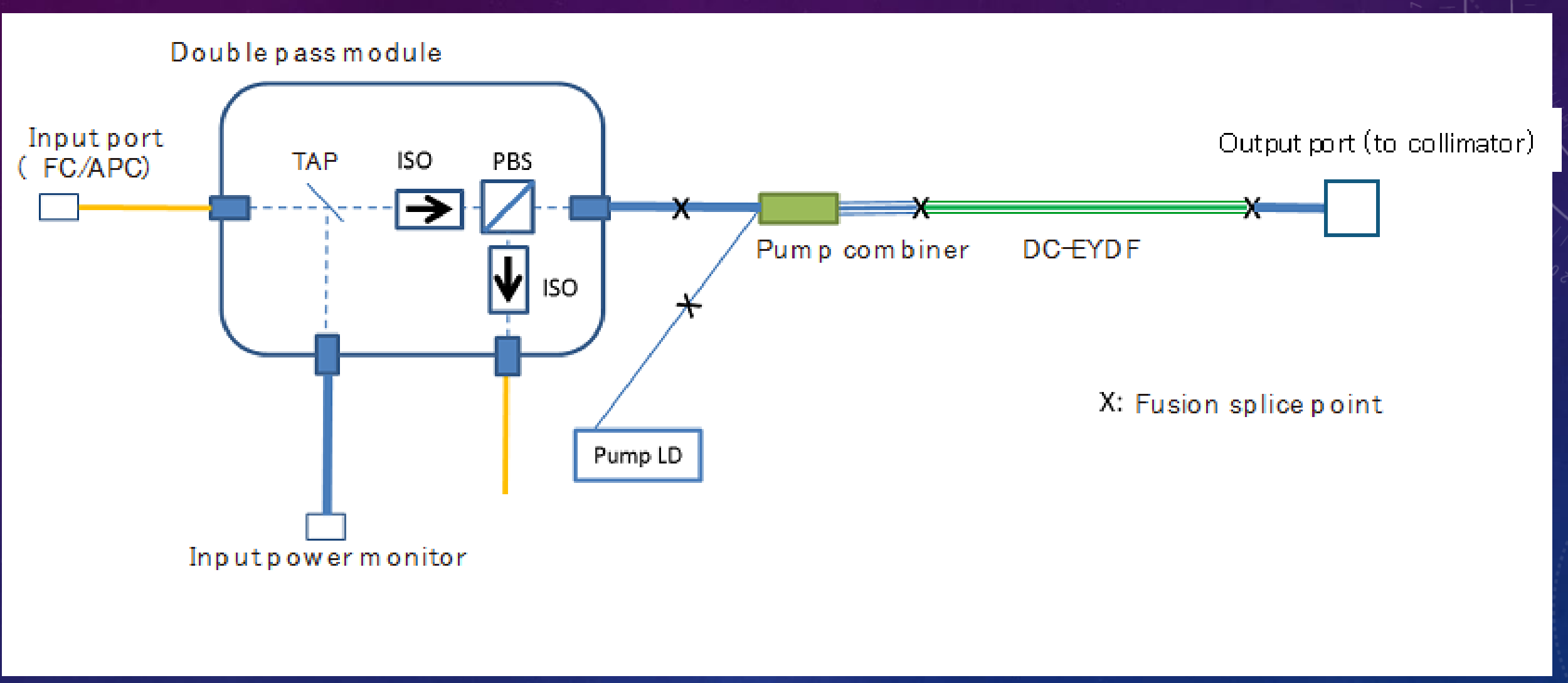




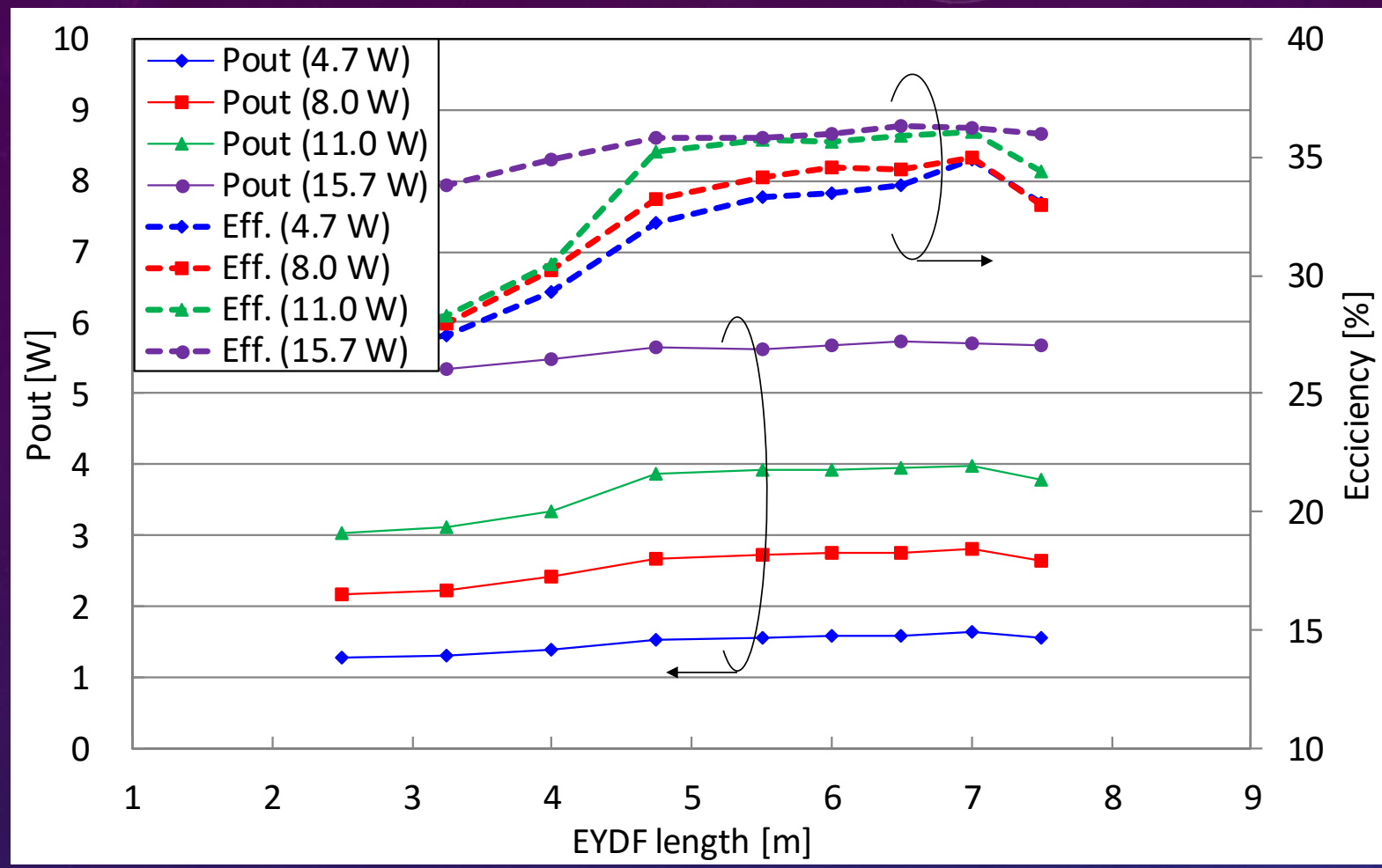

DP-DC-EYDF

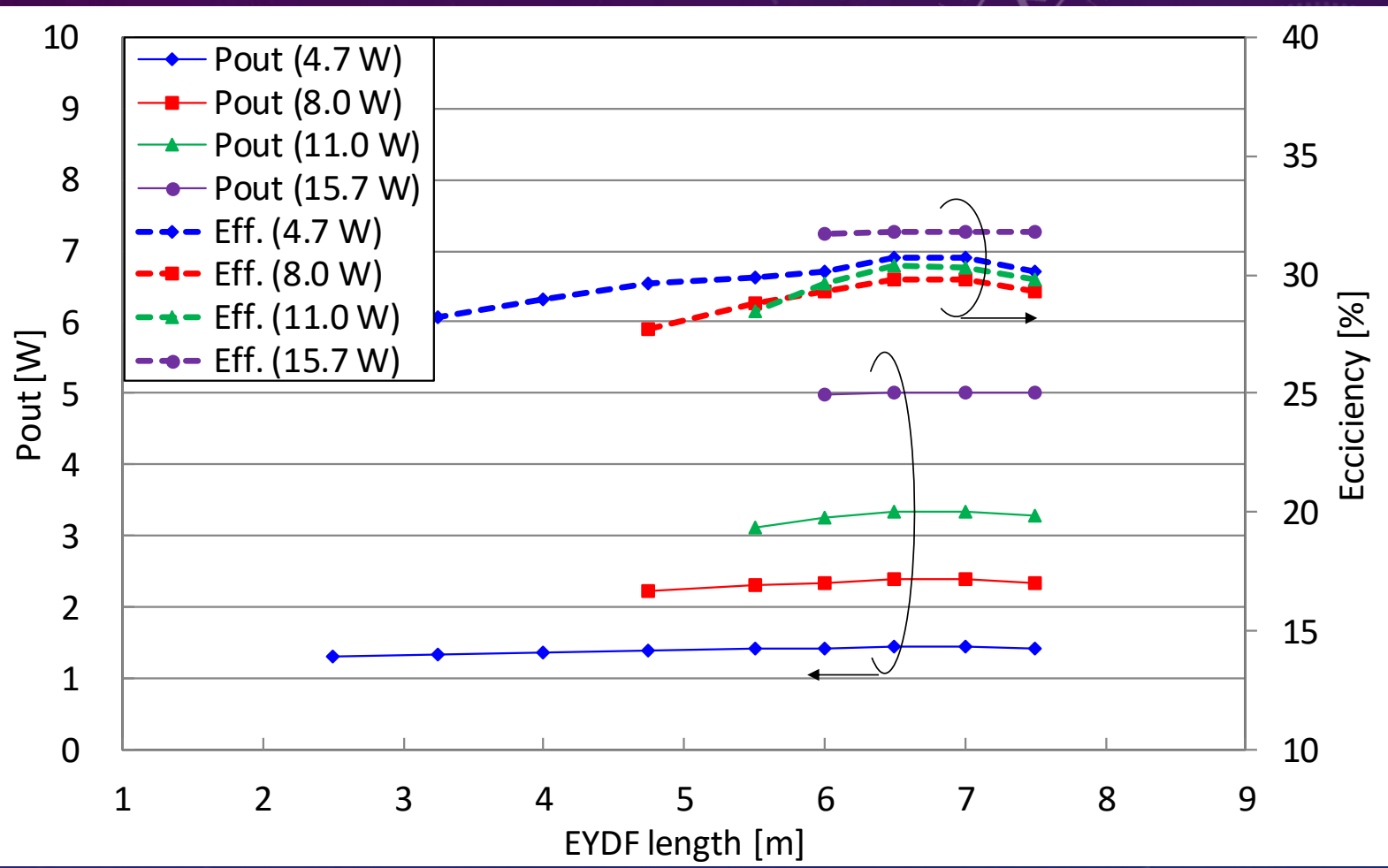

SP-DC-EYDF

$\checkmark$ In case of parasitic Oscillation occurs, no data was obtained 
Achieving higher electrical-to-optical conversion efficiency is one of the most significant issues in realizing optical amplifiers for future space missions.

$>$ This research focused on a DP optical fiber amplifier. The DP amplifier consists of a DP module, a FM module, a pump combiner, a MM pump LD, and DC EYDF.

$>$ An experimental evaluation of the fabricated DP-DC-EYDFA was conducted, and the results indicated that it could achieve optical-to-optical conversion efficiency exceeding $32 \%$ and output power of around $7 \mathrm{~W}$ at the wavelength region between 1540 and $1560 \mathrm{~nm}$,

\section{$\checkmark$ The highest output power ever measured for a DP-DC-EYDFA.}

DP was at least $4.2 \%$ higher than that of the SP type.

$>$ ISSUES; Much higher output power and efficiency, the heat dissipation of EYDF, suppression of parasitic oscillation, reduction of transmission loss, and enhancement of reliability.

\section{$\checkmark$ Need more investigation}

The measured PER of the fabricated DP-DC-EYDFA was $23.6 \mathrm{~dB}$ without using PM EYDF.

$\checkmark$ COST REDUCTION 
1. Back ground

2. Purpose of this research

3. Design and Fabrication of Double-Path, Double-Clad EYDFA

4. Experimental results

\section{Conclusion}




\section{Conclution}

$>$ An experimental/fabricated DP-DC-EYDFA achieve optical-to-optical conversion efficiency exceeding $32 \%$ and output power of around $7 \mathrm{~W}$ at the wavelength region between 1540 and $1560 \mathrm{~nm}$,

$>$ DP was at least $4.2 \%$ higher than that of the SP type.

$>$ The measured PER of the fabricated DP-DC-EYDFA was $23.6 \mathrm{~dB}$ without using PM EYDF.

$>$ We therefore consider that the DP-DC-EYDFA will offer a good solution for future high-power and high-efficiency optical amplifiers.

$>$ OUR FUTUER WORKS; Much higher output power and efficiency, the heat dissipation of EYDF, suppression of parasitic oscillation, reduction of transmission loss, and enhancement of reliability. 


\section{Thank you for your attention! ご清聴ありがとうございました.}

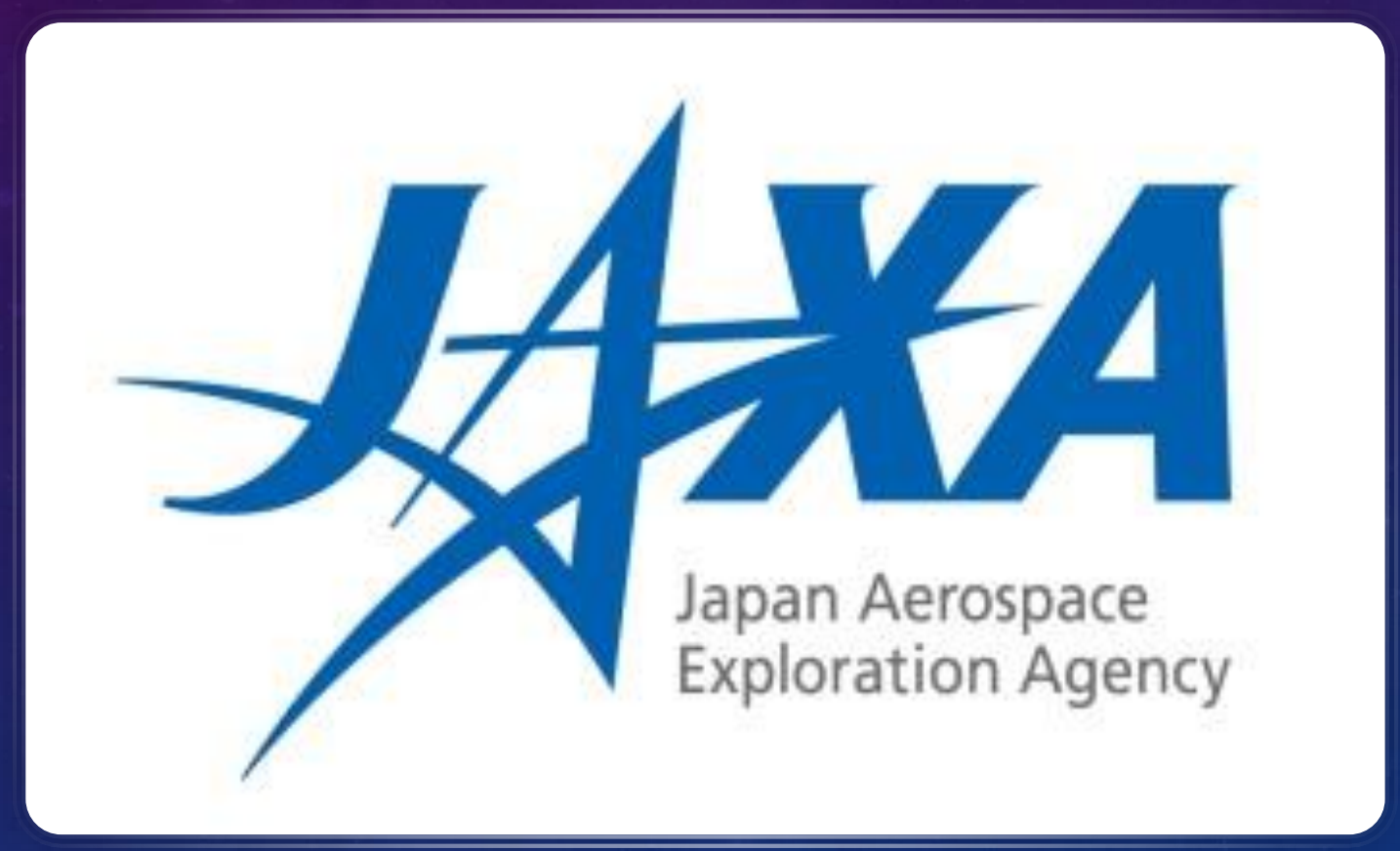




\section{BACK UP}


Band plan in "HDR 1.5um Orange book" under discussion in CCSDS

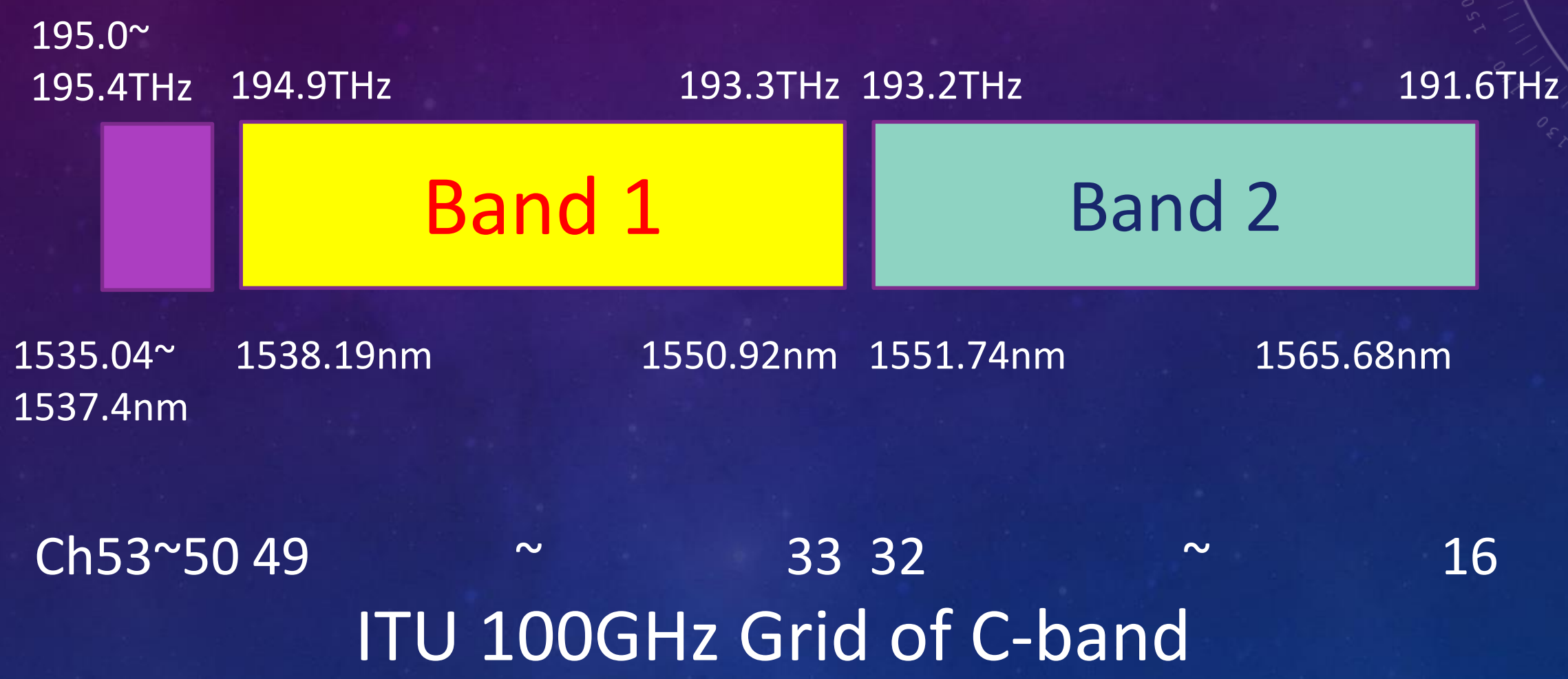

